Table.

\begin{tabular}{lccc}
\hline & Uveitis $(\mathbf{n}=\mathbf{1 0})$ & Non uveitis $(\mathbf{n}=\mathbf{3 1 0})$ & $\mathbf{p}$ \\
\hline Baseline general features & & & \\
Age, years (mean \pm SD) & $42.2 \pm 16.8$ & $46.4 \pm 11.9$ & 0.38 \\
Sex, $\mathbf{n}(\mathrm{m} / \mathrm{w})(\%)$ & $4 / 6(40 / 60)$ & $134 / 176(43.2 / 56.8)$ & 0.90 \\
HLAB27, positive \% & 60 & 11.8 & $<0.01$ \\
Disease Characteristics & & & \\
Axial arthritis, \% & 40.0 & 37.0 & 0.88 \\
Peripheral arthritis, \% & 80.0 & 72.9 & 0.89 \\
Hip affection, \% & 30.0 & 20.0 & 0.71 \\
Enthesitis, \% & 60.0 & 40.5 & 0.55 \\
Dactylitis, \% & 20.0 & 29.5 & 0.77 \\
Scores & & & \\
BASDAI (mean \pm SD) & $3.3 \pm 2.08$ & $1.6 \pm 1.9$ & 0.26 \\
BASFI (mean \pm SD) & $2.7 \pm 1.9$ & & 0.31 \\
\hline
\end{tabular}

Disclosure of Interests: Iñigo González-Mazón: None declared, Lara Sanchez-Bilbao Grant/research support from: Pfizer, Natalia Palmou-Fontana: None declared, David Martinez-Lopez: None declared, Susana Armesto: None declared, Miguel A González-Gay Grant/research support from: Pfizer, Abbvie, MSD, Speakers bureau: Pfizer, Abbvie, MSD, Ricardo Blanco Grant/research support from: AbbVie, MSD, and Roche, Speakers bureau: AbbVie, Pfizer, Roche, Bristol-Myers, Janssen, and MSD

DOI: 10.1136/annrheumdis-2020-eular.5499

\section{AB0778 ASSOCIATION BETWEEN PATIENT-REPORTED OUTCOMES AND DISEASE ACTIVITY IN BIMEKIZUMAB-TREATED PATIENTS WITH PSORIATIC ARTHRITIS}

L. Gossec ${ }^{1}$, P. J. Mease ${ }^{2}$, A. B. Gottlieb ${ }^{3}$, A. Ogdie ${ }^{4}$, D. Assudani ${ }^{5}$, J. Coarse ${ }^{6}$, B. Ink ${ }^{5}$, L. C. Coates ${ }^{7}{ }^{1}$ Sorbonne Université and Pitié Salpétriere Hospital, Paris, France; ${ }^{2}$ Swedish Medical Center and University of Washington, Seattle, United States of America; ${ }^{3}$ lcahn School of Medicine at Mount Sinai, New York, United States of America; ${ }^{4}$ Hospital of the University of Pennsylvania, Philadelphia, United States of America; ${ }^{5}$ UCB Pharma, Slough, United Kingdom; ${ }^{6}$ UCB Pharma, Raleigh, United States of America; ${ }^{7}$ University of Oxford, Oxford, United Kingdom

Background: Bimekizumab (BKZ) is a humanised IgG1 monoclonal antibody, which selectively neutralises interleukin (IL)-17A and IL-17F. There is support for the BKZ mechanism of action as a novel therapeutic approach for psoriatic arthritis (PsA). ${ }^{1-3}$ The phase $2 \mathrm{~b}$ dose-ranging BE ACTIVE study assessed the efficacy and safety of BKZ in patients (pts) with PsA; data are reported elsewhere. ${ }^{4}$ Patient-reported outcomes (PROs) are increasingly recognised as important endpoints in clinical trials. ${ }^{5}$ The Psoriatic Arthritis Impact of Disease-9 (PsAID-9) questionnaire was specifically developed to assess health-related quality of life (QoL) in pts with $\mathrm{PsA}^{5}$ and its validity in clinical practice has been demonstrated. ${ }^{5-6}$

Objectives: To report the association between PsAID-9 score (a PRO) and disease activity response (very low disease activity [VLDA], minimal disease activity [MDA] or Disease Activity Index for Psoriatic Arthritis [DAPSA] remission) during 48 weeks' (wks') BKZ treatment.

Methods: Details of the study design (NCT02969525) are reported elsewhere. ${ }^{4}$ Here, we report the proportion of pts who achieved a PSAID-9 score $\leq 3$, and the association between PsAID-9 score at Wk 48 (range 0-10, where 10 corresponds to worst QoL) and VLDA/MDA (binary states of disease control) or DAPSA (range $0 \rightarrow 28$ where $0-4$ is remission, $5-14$ is low, $15-28$ is moderate, and $>28$ is high disease activity) at Wk 12 .

Results: Across 206 randomised pts at baseline, $66.5 \%$ had psoriasis body surface area $(\mathrm{BSA}) \geq 3 \%, 18.9 \%$ had prior tumour necrosis factor inhibitor (TNFi) exposure, and $63.6 \%$ received concomitant methotrexate. A substantial proportion of pts achieved MDA and/or DAPSA remission by Wk 12 , which generally increased through to Wk 24 and 48 (Table 1). The $160 \mathrm{mg} \mathrm{BKZ}$ group saw the highest Wk 48 rates of MDA response $(60.0 \%)$ and DAPSA remission $(45.0 \%)$ (Table 1). The proportion of pts achieving a PsAID-9 score $\leq 3$ was consistently high across all active treatment arms (Figure 1). PsAID-9 score was consistently lower (indicating better QoL) for pts with VLDA or MDA, and those in DAPSA remission (Figure 2), indicating that low disease activity was associated with improved PROs.

Conclusion: In BKZ-treated pts, improvements in PsAID-9 were associated with achievement of VLDA/MDA response and DAPSA remission. These results suggest that pts achieving higher disease control have improved QoL.

References:

[1]Glatt S. Ann Rheum Dis 2018;77:523-32; 2. Glatt S. Br J Clin Pharmacol 2017;83:991-1001; 3. Papp KA. J Am Acad Dermatol 2018;79:277-86; 4. Ritchlin CT. Ann Rheum Dis 2019;78:127-8; 5. Gossec L. Ann Rheum Dis 2014;73:1012-19; 6. Johnson K. Semin Arthritis Rheum 2019;49:241-45.
Table 1. MDA and DAPSA responder rates

\begin{tabular}{lcccccc}
\hline & \multicolumn{3}{c}{ MDA (\%) [a] } & \multicolumn{4}{c}{$\begin{array}{c}\text { DAPSA } \\
\text { remission (\%) [b] }\end{array}$} \\
\cline { 2 - 8 } Treatment arm & Wk 12 & Wk 24 & Wk 48 & Wk 12 & Wk 24 & Wk 48 \\
\hline BKZ 160 mg ( $n=40)$ & 47.5 & 50.0 & 60.0 & 20.0 & 35.0 & 45.0 \\
BKZ 160 mg LD (n=37) [c] & 43.2 & 59.5 & 54.1 & 29.7 & 48.6 & 37.8 \\
BKZ 320 mg (n=41) & 29.3 & 36.6 & 46.3 & 12.2 & 19.5 & 34.1 \\
\hline
\end{tabular}

[a] DBS, pts with missing data were counted as non-responders; [b] DBS, missing data are imputed using last observation carried forward; [c] $160 \mathrm{mg}$ with $320 \mathrm{mg}$ LD at baseline. BKZ: bimekizumab; DAPSA: Disease Activity Index for Psoriatic Arthritis; DBS: dose-blind set; LD: loading dose; MDA: minimal disease activity.
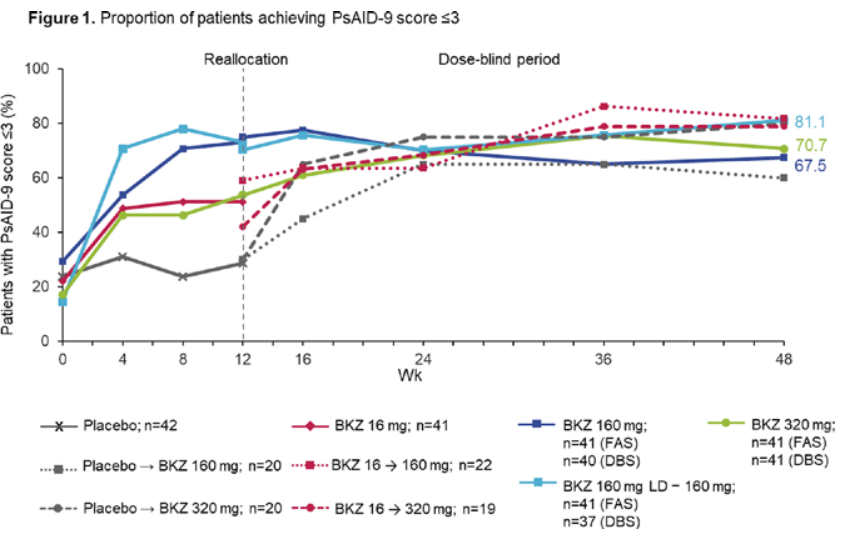

Figure 2. Association between PSAID-9 and VLDA, MDA, and DAPSA disease states at Wk 48

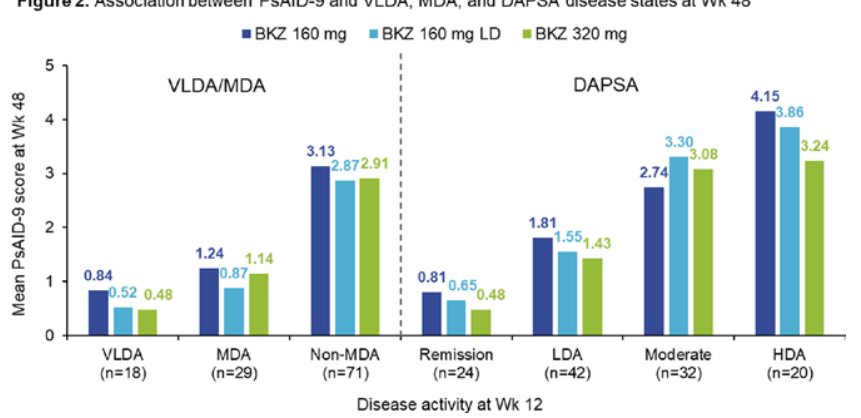

Acknowledgments: This study was funded by UCB Pharma. Editorial services were provided by Costello Medical.

Disclosure of Interests: Laure Gossec Grant/research support from: Lilly, Mylan, Pfizer, Sandoz, Consultant of: AbbVie, Amgen, Biogen, Celgene, Janssen, Lilly, Novartis, Pfizer, Sandoz, Sanofi-Aventis, UCB, Philip J Mease Grant/research support from: Abbott, Amgen, Biogen Idec, BMS, Celgene Corporation, Eli Lilly, Novartis, Pfizer, Sun Pharmaceutical, UCB - grant/research support, Consultant of: Abbott, Amgen, Biogen Idec, BMS, Celgene Corporation, Eli Lilly, Novartis, Pfizer, Sun Pharmaceutical, UCB - consultant, Speakers bureau: Abbott, Amgen, Biogen Idec, BMS, Eli Lilly, Genentech, Janssen, Pfizer, UCB - speakers bureau, Alice B Gottlieb Grant/ research support from:: Research grants, consultation fees, or speaker honoraria for lectures from: Pfizer, AbbVie, BMS, Lilly, MSD, Novartis, Roche, Sanofi, Sandoz, Nordic, Celltrion and UCB., Consultant of:: Research grants, consultation fees, or speake honoraria for lectures from: Pfizer, AbbVie, BMS, Lilly, MSD, Novartis, Roche, Sanofi, Sandoz, Nordic, Celltrion and UCB., Speakers bureau:: Research grants, consultation fees, or speaker honoraria for lectures from: Pfizer, AbbVie, BMS, Lilly, MSD, Novartis, Roche, Sanofi, Sandoz, Nordic, Celltrion and UCB., Alexis Ogdie Grant/research support from: Pfizer to Penn, Novartis to Penn, Amgen to Forward/NDB, Consultant of: Abbvie, Amgen, Bristol-Myers Squibb, Celgene, Corrona, Janssen, Eli Lilly, Novartis, Pfizer, Deepak Assudani Employee of: UCB Pharma, Jason Coarse Employee of: UCB Pharma, Barbara Ink Shareholder of: GlaxoSmithKline and UCB Pharma, Employee of: UCB Pharma, Laura C Coates: None declared DOI: 10.1136/annrheumdis-2020-eular.4204

\section{AB0779 \\ DOES DACTYLITIS/ENTESITIS PREDICT THE RESPONSE TO A SPECIFIC BIOLOGICAL TREATMENT IN PSORIATIC ARTHRITIS?}

C. Guillén-Astete $^{1,2}$, P. Zurita-Prada ${ }^{2,3}$, C. Urrego-Laurín ${ }^{2,3} \cdot{ }^{1}$ Hospital Ramón y Cajal, Madrid, Spain; ${ }^{2}$ Universidad Europea de Madrid (Campus Villaviciosa), Villaviciosa de Odón, Spain; ${ }^{3}$ University Hospital Moncloa, Madrid, Spain 